\section{Higher sight}

\section{Glyn Humphreys}

Synesthesia: A Union of the Senses. By Richard E. Cytowic. Springer-Verlag: 1989. Pp. 354. DM148, £53, \$75.

A CHARACTER in a popular British television programme experiences pink days, yellow hopes and dreams that are all the colours of the rainbow. In some people, such associations between abstract concepts and imageable colours seem to occur involuntarily and to be both vivid and memorable. The condition of experiencing such involuntary and perceptable cross-associations is called a synesthesia.

Syndromes such as synesthesia are rarely dealt with in psychological science. Many basic questions have simply not been put: are synesthetic experiences real or merely examples of expansive and metaphoric use of language; what is the cause of such experiences; what are the relations between different forms of synesthetic experience, and between these experiences and other elaborate associations (as when people develop predigious and individual mnemonic strategies)?

Luria touched on some of these points in The Mind of the Mnemonist (Basic Books; London, 1968), but subsequently they have all too often been subsumed under the banner of romantic neurology. To some extent this has occurred because current theoretical accounts of brain and behaviour have little to say about 'superabundant' states. Syndromes in which particular behavioural functions are impaired (such as reading, writing or recognition of visual objects) can be understood in terms of the lesioning of one or more components in the complex system underlying the behaviour. Syndromes reflecting behavioural patterns over and above those that normally occur are less easy to relate to the operation of identifiable processing components. This can be taken as an indictment of current theorizing. Rigorous study of such syndromes, in which basic questions are answered, could immeasurably enrich our understanding of the relationships between brain and behaviour.

In his book, Richard Cytowic attempts to provide the first complete account of synethesia. But problems abound, not least the definition of the syndrome. Cytowic cites many examples of what he classes as synesthetic experience: in many cases, people experience the perception of colour or of simple visual shapes (lines, squares, circles or simple random patterns) in response to particular stimuli music and numbers seem two common elicitors. In other instances, taste, smell or tactile experiences are reported. But what of artistic experience and expression? Cytowic includes a chapter on synesthesia and art, incorporating an interview in which David Hockney discusses his use of colour in opera design. This would be fine, if only the lines between empirical finding and speculation were clearly demarcated. It is a pity that they are not, by clouding the boundaries, Cytowic fails to provide the groundwork for future studies.

He does, however, make many useful observations. For instance, synesthetic experiences such as cross-modal colour associations seem to take a consistent form, and are often associated with similar stimuli, in different people. They are experienced from an early age, involving simple rather than complex shapes or known objects. The preponderance of synesthetites are female, often from families where other members report similar experiences. In one case studied in some detail by Cytowic and his colleagues, the subject experienced a marked decrease in cortical blood flow during synthetic experiences which correlated closely to variations in the synesthetic experience produced by the intake of ethanol and amyl nitrate. Such observations suggest that there is a real perceptual phenomenon underlying the experience. But without attempts to draw boundaries between different types of synesthetic experiences, or to establish empirical means of separating synethesia from metaphorical expression, the sceptical reader is left unconvinced. I longed to know what would happen to some of the synesthetites in standardized tasks of experimental psychology, such as colour-matching of numbers (would they be impaired if numbers are drawn in colours other than those with which they are normally associated?) or the Stroop colour word-naming task. Such evidence is sadly lacking.

Cytowic proposes that synesthetic experiences arise from activity in limbic structures in the brain under conditions where cortical activity is decreased. This is an interesting idea, and consistent with the cerebral blood-flow work. But no sooner does Cytowic discuss "the hippocampus model for synesthesia" (p. 174) than he proposes that "the neural real estate for synesthesia resides in the left (cerebral) hemisphere". It is very hard at times to hold on to exactly what is being proposed. This is indicative of the overexpansive writing style that hides rather than illuminates the syndrome.

Many perceptual phenomena are treated in a cavalier way. Early on, Cytowic raises the example of colour constancy to argue that the world is not as we see it. Well yes, but then colour constancy is not an hallucination; rather it is based on the constraining influence of neighbouring surfaces in the visual field, as the author later makes clearer when he discusses Land's retinex theory of colour vision. In his discussion of 'blindsight', Cytowic argues that even when patients cannot detect the presence of a shape in their blind visual field, they can nevertheless show good shape discrimination. In fact, Weiskrantz in his book Blindsight (Oxford University Press, 1986) showed that such patients have good orientation rather than shape discrimination. The list is extensive. Yet hidden beneath the florid writing are the glimmerings of an interesting phenomenon. Syndromes such as synesthesia ought to be the subject of more rigorous scientific study. If Cytowic prompts us towards that end, then his book will have accomplished no mean feat.

Glyn Humphreys is in the Cognitive Science Research Centre at the University of Birmingham, Edgbaston, Birmingham B15 2TT, UK.

\section{Cruel world}

\section{Andrew Holmes-Siedle}

My Life with the Printed Circuit. By Paul Eisler. Associated University Presses, 440 Forsgate Drive, Cranbury, NJ 08512, USA 25 Sicilian Avenue, London WC1A 2QH: 1989. Pp.170.£13.95, \$29.50.

PAUL Eisler invented the printed circuit, a revolutionary method of manufacturing electronic hardware, in 1936. His adventures make instructive reading, especially for the engineer and innovator. Out of a detailed, clearly written story of a technical life (the useful bibliography is by Mari Williams) emerge many contrasts between the outlook of an engineer and of a businessman. This is not a hard-luck story, but it certainly is a cautionary tale.

Eisler's is not a plaintive account, for he has been widely honoured for his inventions and he has made a fair living as a research manager and consultant. $\mathrm{He}$ does not seem particularly bitter that many others have made millions by flouting his patents, but in this book he goes further than most to describe in detail the sheer sleaziness of the business practices that he encountered. I do not get the feeling that this nastiness is particular to the electronic industry - it is probably transferred unmodified from other manufacturing industries. The reader may be angered by the contrast between the grubby practices described and the clean technical promise of Eisler's invention (and of electronic systems as a whole). It is sad to find the same old grubbiness in that shining new world.

Few people realize that the printed circuit was invented long before the transistor. The invention was conceived in 1936 when Eisler, an Austrian engineer forbidden to take employment in Britain, was working on inventions in his small room in Hampstead, north London. A printing firm took up the printed circuit idea because the technique could be 